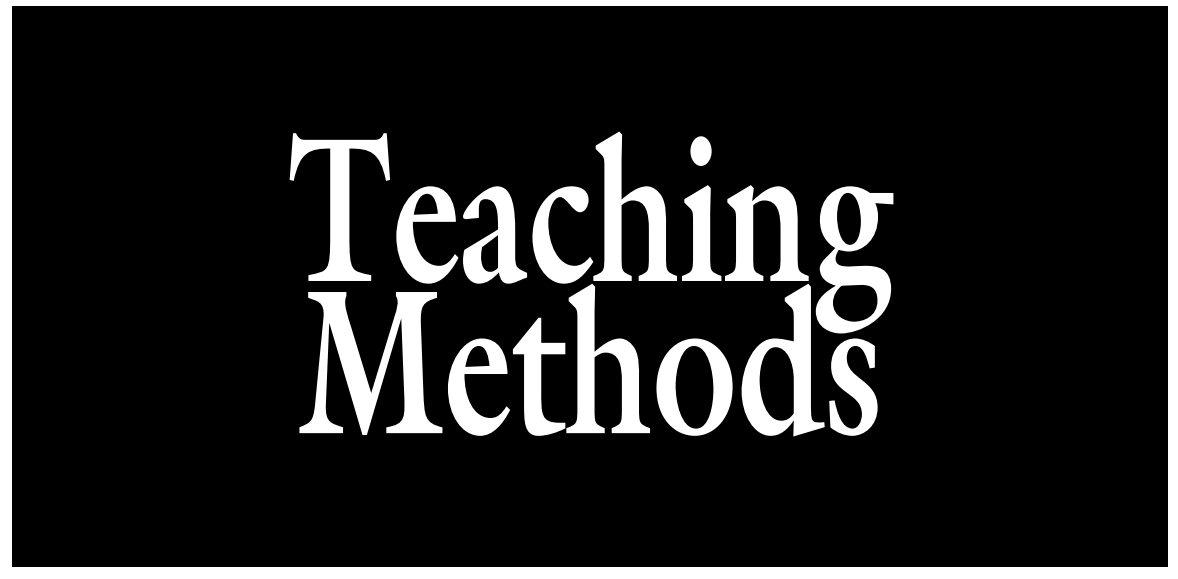

\section{A Laboratory Exercise in Physiological Seed Dormancy Using Eastern Redbud}

\author{
Servet Caliskan ${ }^{1}$, Sharon T. Kester ${ }^{2}$, and Robert L. Geneve ${ }^{2,3}$
}

AdDitional INDEX words. Cercis canadensis, distance learning, endogenous dormancy, education, germination

SUMMARY. A laboratory exercise is presented that demonstrates the impact of seed coverings and hormones on seed dormancy and release in seeds with endogenous, physiological dormancy. The materials and methods are simple and inexpensive and can be accomplished as an on-campus laboratory or as a distance education exercise. The execution of the laboratory is rapid ( $\approx 1$ hour), and the results are obtained in 2 weeks. The exercise generates an opportunity for the discussion of a complex subject that involves the interaction of two tissue types within the seed (the embryo vs. the seed coverings) and nicely illustrates their role in seed dormancy maintenance.

$\mathrm{P}$ rimary physiological dormancy is a basic concept for courses that emphasize general plant propagation or specific courses in seed biology or technology. Primary seed dormancy is a condition where seeds will not germinate even when the environmental conditions (water, temperature, light, and aeration) are permissive for germination (Hartmann et al., 2011). Not only does seed dormancy prevent immediate germination, it also regulates the time, conditions, and location where germination will occur. In nature, different kinds of dormancy have evolved to aid the survival of a species by programming germination for particularly favorable times in the annual seasonal cycles. The major type of seed dormancy seen in temperate plant species is classified as primary, endogenous, physiological

${ }^{1}$ Department of Silviculture, Faculty of Forestry, Istanbul University, 34473 Bahcekoy, Sariyer, Istanbul Turkey

${ }^{2}$ Department of Horticulture, University of Kentucky, Lexington, KY 40546

${ }^{3}$ Corresponding author. E-mail: rgeneve@uky.edu. dormancy (Baskin and Baskin, 1998). Therefore, the purpose of this manuscript is to describe an easily performed laboratory experiment suitable for undergraduate courses (both on campus and for distance learning), which demonstrates the mechanism for dormancy release in seeds with endogenous, physiological dormancy.

Eastern redbud (Cercis canadensis) is a good model system to illustrate dormancy maintenance and release in seeds with physiological dormancy because there is available published research concerning eastern redbud dormancy to support student laboratory reports (Geneve, 1991; Jones and Geneve, $1995)$ and the seeds are widely available commercially or from local collections. Additionally, eastern redbud seed is fairly large and easy for students to manipulate during laboratory.

The learning outcomes for this laboratory exercise are that a student will understand the role seed coverings play in maintaining seed dormancy, be able to explain the concept of embryo growth potential and the contribution of growth potential to seed dormancy release, be able to describe the possible roles plant hormones play in seed dormancy maintenance and release, be able to recognize different tissue types in a seed, and have an appreciation for the interaction of these tissues related to seed dormancy.

\section{Laboratory exercise materials and methods}

This laboratory exercise can be performed as an on-campus activity or easily fit into a distance education format by mailing individual students treated seeds, petri dishes with germination paper (treated with or without the hormone solution), and a razor blade.

Eastern redbud seeds can be purchased from a seed company or collected from local trees. All seeds should be previously scarified for $40 \mathrm{~min}$ in concentrated sulfuric acid $\left(\mathrm{H}_{2} \mathrm{SO}_{4}\right)$ to remove physical dormancy and permit imbibition. Alternatively, seeds can be hot water scarified in $70{ }^{\circ} \mathrm{C}$ water for $10 \mathrm{~min}$. Expect $100 \%$ imbibition with acid scarification and $\approx 75 \%$ imbibition with hot water scarification. Scarified seeds can be stored for weeks dry in a sealed container at $5{ }^{\circ} \mathrm{C}$.

Seven treatments are included in the laboratory exercise: 1 ) intact seeds stratified at $5{ }^{\circ} \mathrm{C}$ for 6 to 8 weeks, 2) intact seeds without prior stratification, 3) intact seeds without prior stratification imbibed in $100 \mu \mathrm{M}$ gibberellic acid $\left.\left(\mathrm{GA}_{3}\right), 4\right)$ intact seeds without prior stratification with the seedcoat split at hilum, 5 ) intact seeds without prior stratification with the seedcoat split at end opposite hilum, 6) embryos excised from hydrated seeds without prior stratification and germinated on water, and 7) embryos

\begin{tabular}{llll}
\hline $\begin{array}{l}\text { Units } \\
\begin{array}{l}\text { To convert U.S. to SI, } \\
\text { multiply by }\end{array}\end{array}$ & U.S. unit & SI unit & $\begin{array}{l}\text { To convert SI to U.S., } \\
\text { multiply by }\end{array}$ \\
\hline 29.5735 & fl oz & $\mathrm{mL}$ & 0.0338 \\
2.54 & inch $(\mathrm{es})$ & $\mathrm{cm}$ & 0.3937 \\
$\left({ }^{\circ} \mathrm{F}-32\right) \div 1.8$ & ${ }^{\circ} \mathrm{F}$ & ${ }^{\circ} \mathrm{C}$ & $\left({ }^{\circ} \mathrm{C} \times 1.8\right)+32$
\end{tabular}


excised from hydrated seeds without prior stratification and placed in $25 \mu \mathrm{M}$ abscisic acid (ABA).

Eastern redbud seeds are stratified by placing $\approx 100$ seeds (previously

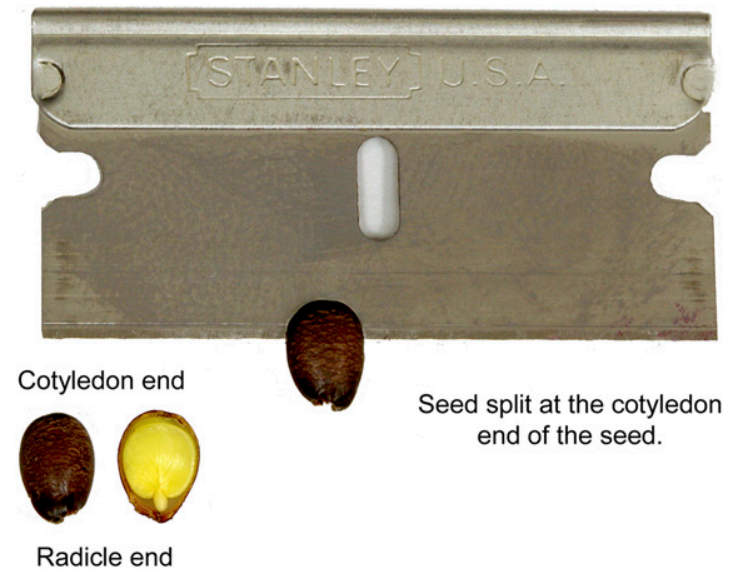

Fig. 1. Razor blade technique for performing surgery on eastern redbud seeds showing the different orientation and location of the razor blade cuts.

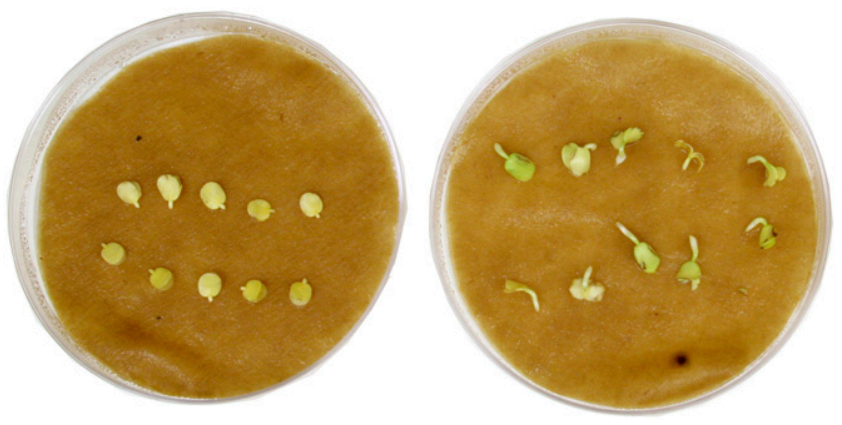

Fig. 2. Embryos of eastern redbud excised from their seed coverings and placed on moist germination paper in a petri dish before and after germination. sand. For most seed lots, seeds are fully released from dormancy after 8 weeks of stratification at $5{ }^{\circ} \mathrm{C}$. Seeds often become infested with surface fungi during stratification that should be washed off and damaged seeds discarded. If necessary, cleaned, stratified seeds can be dried for brief periods (usually up to 2 months) without significant impact on dormancy release, which may make mailing simpler for a distance education laboratory.

All seeds and isolated embryos should be germinated at 20 to $25^{\circ} \mathrm{C}$ in the light $\left(\approx 40 \mu \mathrm{mol} \cdot \mathrm{s}^{-1} \cdot \mathrm{m}^{-2}\right.$ at $\approx 12$ inches from a tandem pair of $40-\mathrm{W}$ fluorescent lamps) using $8.5-\mathrm{cm}$ diameter plastic petri dishes containing one piece of germination paper (Anchor Paper Co., St. Paul, $\mathrm{MN}$ ) wetted with $5 \mathrm{~mL}$ water or hormone solution. Petri dishes should be sealed with parafilm (Pechiney Plastic Packaging Co., Chicago, IL) along the edge to reduce water loss from the dishes. Alternatively, dishes can be place in a closed breathable, polyethylene bag. For the $\mathrm{GA}_{3}$ treatment, dry scarified seeds can be imbibed for $24 \mathrm{~h}$ in $100 \mu \mathrm{M} \mathrm{GA}_{3}$ before moving to petri dishes or dry scarified seeds can be placed directly into petri dishes containing the $\mathrm{GA}_{3}$ solution.

The seedcoat splitting and removal treatments should be made to seeds imbibed at least $48 \mathrm{~h}$. Seedcoat splitting and removal treatments

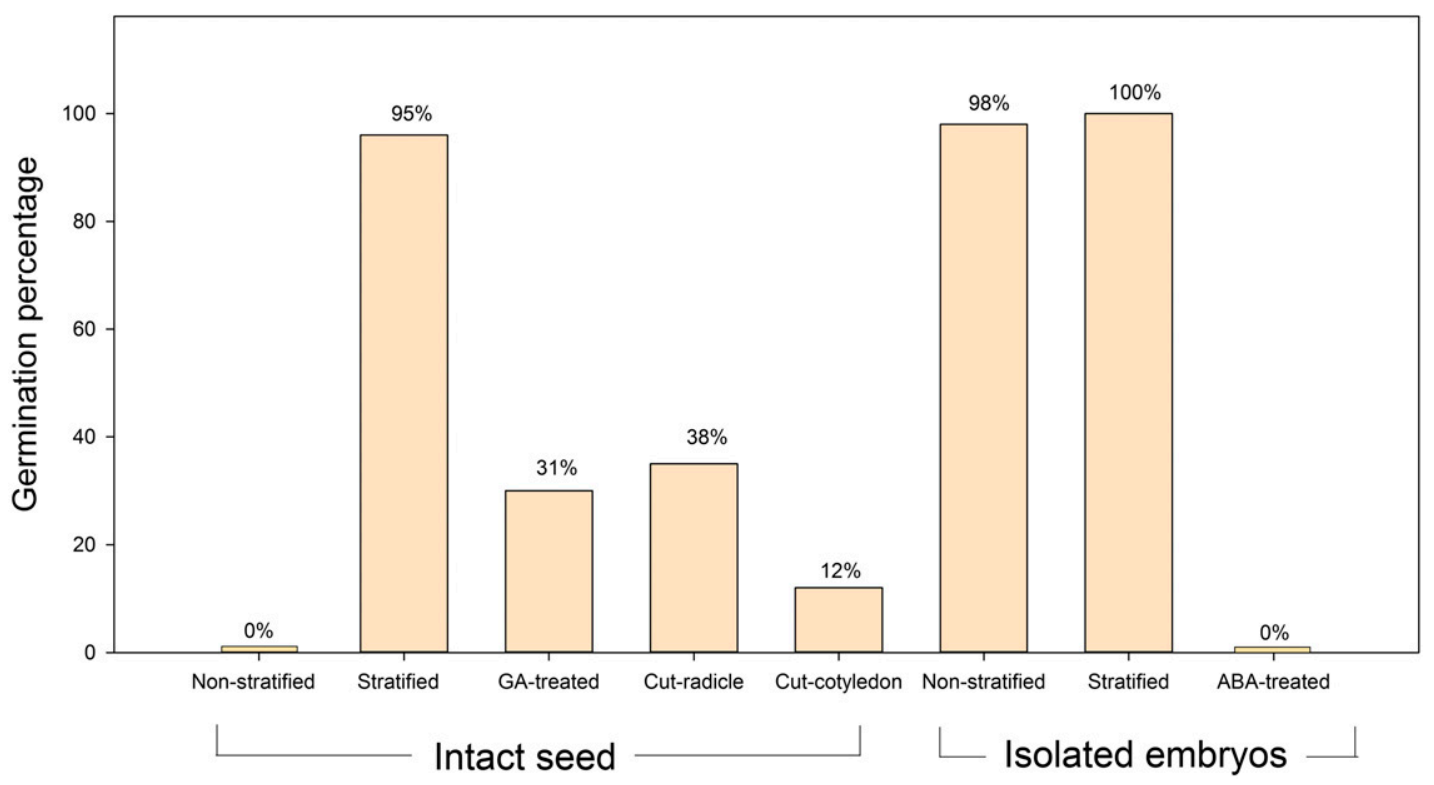

Fig. 3. Typical results from a class experiment on seed germination treatments in eastern redbud to demonstrate effects on seed physiological dormancy; GA = gibberellic acid, ABA = abscisic acid. 
can be accomplished using a singleedge razor blade and forceps (Fig. 1). The seedcoat should be split following the wide edge of the seed either at the hilum (radicle end) or the end opposite the hilum (cotyledon end). The blade needs to cut completely through the seedcoat, but not deep enough to significantly damage the radicle or cotyledon. Embryos are excised and isolated from the seedcoat and enclosing endosperm by cutting along the cotyledon edge of the seed and gently separating the two halves of the seed exposing the embryo (Fig. 2).

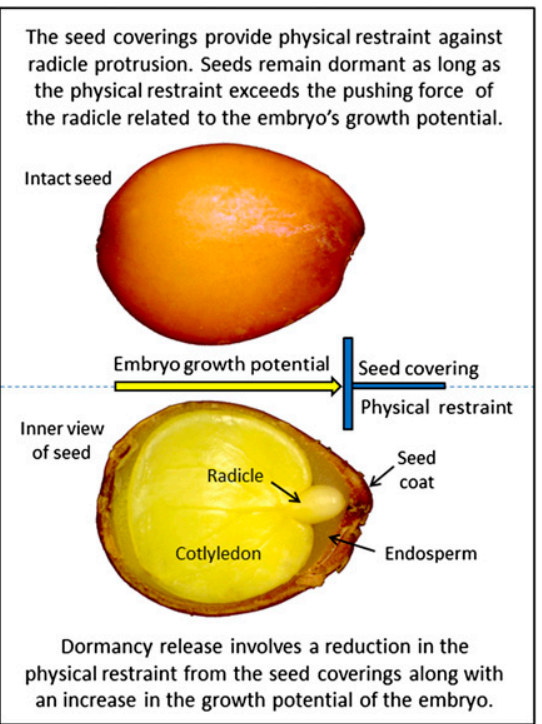

Fig. 4. A conceptual model for dormancy release in a seed (such as eastern redbud) with endogenous, physiological dormancy.
Students can work individually or in teams of two students. To reduce materials, one petri dish can be used per treatment for each student (team) and treatments replicated across each member of the class. Germination percentages for excised embryos are taken after $7 \mathrm{~d}$ and for intact seeds after 7 and $14 \mathrm{~d}$. Seeds are considered germinated after radicle emergence from the seedcoat or a geotropic response on the elongating radicle. Data from each group can be input into a spreadsheet and a bar graph generated for immediate class discussion or used for a future laboratory report. Typical class results are shown in Fig. 3.

\section{Discussion of class results}

Typically, intact scarified seeds without chilling stratification will remain dormant and not germinate. Even though excised from dormant (nonstratified) seeds, isolated embryos germinate at near $100 \%$. Seeds that are split at the radicle or cotyledon end should germinate, but the percentages should be higher in those split at the radicle end. It is typical for seeds split at the cotyledon end to "push" their way out the cut end of the seed, while those split at the radicle end, germinate more normally with the radicle emerging from the seed. Germination in intact stratified seeds will approach 90\% depending on the length of stratification. Intact, nonstratified seeds treated with $\mathrm{GA}_{3}$ often show between 25\% and 50\% germination, while excised embryos placed on ABA will not germinate.

The concept of dormancy maintenance and release in seeds with endogenous, physiological dormancy can be confusing for students because it involves the interaction of two tissue types within the seed-the embryo vs. the seed coverings (usually the endosperm and seedcoat). During dormancy release, there are physiological changes that occur within the embryo to permit the embryo to exert more pressure on the enclosing seed coverings to initiate radicle protrusion. The basic model for maintenance of physiological dormancy is that the nonstratified embryo lacks the growth potential (Baskin and Baskin, 1971; Finch-Savage and Leubner-Metzger, 2006) to allow the radicle to escape the restraint of the seed coverings (Fig. 4). Growth potential is the force used by the radicle to penetrate the seed coverings. Many species with physiological dormancy have embryos that germinate normally if the seed coverings over the radicle are removed (the exception are those with deep physiological dormancy). The physical strength of the endosperm and seed coverings have been shown to restrict germination in both herbaceous [lettuce (Lactuca sativa), pepper (Capsicum annuum), and tomato (Solanum lycopersicum)] and woody [eastern redbud and lilac (Syringa vulgaris)] plants (Hartmann et al., 2011). Dormancy in these species is overcome by weakening of the seed coverings, by

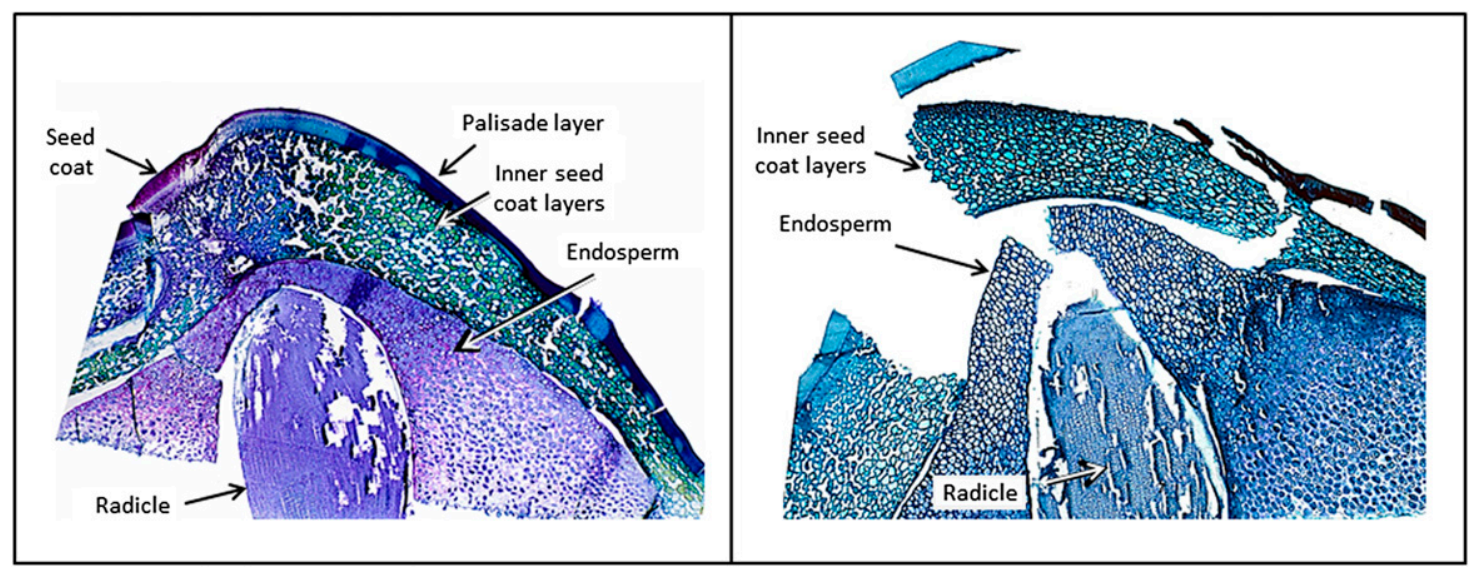

Fig. 5. General seed morphology in eastern redbud seeds related to seed germination. The tissue covering the radicle is known as an "endosperm cap." Endosperm caps are typical in seeds with physiological dormancy and important in maintaining dormancy. Notice how there are physiological changes in the endosperm covering the radicle. Before germination, endosperm cells over the radicle show less staining than endosperm not covering the radicle. This is an indication of enzymatic activity possibly involved in weakening this portion of the endosperm. Also notice that the endosperm layer stretched before breaking on a single plane over the radicle. The seedcoat actually ruptures long before there is a tear in the endosperm layer. 
increasing growth potential in the embryo, or by a combination of seed covering and embryo effects.

The seedcoat splitting and removal treatments nicely demonstrate the importance of the seed coverings in maintaining dormancy. In eastern redbud (like many other species), it is apparently the endosperm cells in the endospermic cap covering the radicle that is responsible for maintaining dormancy (Fig. 5). Notice how the endosperm appears to "snap" under the pressure of the expanding radicle (Fig. 5). Therefore, completely removing the seed coverings or cutting through the endosperm layer at the radicle end of the seed allows the radicle to escape and germinate. It is thought that the endosperm plays a major role in restraining radicle elongation [either chemically (i.e., ABA), physically, or both]. In species where the endosperm can be easily separated from the seedcoat, the endosperm has been shown to be sufficient to maintain dormancy. The possible antagonistic roles of gibberellin and $\mathrm{ABA}$ in dormancy maintenance are suggested by the hormone treatments (Kucera et al., 2005) and can be discussed in the context of the basic dormancy model presented in Fig. 4.

\section{Literature cited}

Baskin, C.C. and J.M. Baskin. 1971. Effect of chilling and gibberellic acid on growth potential of excised embryos of Ruellia humilis. Planta 100:365-369.

Baskin, C.C. and J.M. Baskin. 1998. Seeds, ecology, biogeography, and evolution of dormancy and germination. Academic Press, New York, NY.
Finch-Savage, W.E. and G. LeubnerMetzger. 2006. Seed dormancy and the control of germination. New Phytol. 171:501-526.

Geneve, R.L. 1991. Seed dormancy in eastern redbud (Cercis canadensis). J. Amer. Soc. Hort. Sci. 116:85-88.

Hartmann, H.T., D.E. Kester, F.T. Davies, Jr., and R.L. Geneve. 2011. Hartmann and Kester's plant propagation: Principles and practices. 8th ed. PrenticeHall, Englewood Cliffs, NJ.

Jones, R.O. and R.L. Geneve. 1995. Seedcoat structure related to germination in eastern redbud (Cercis canadensis L.). J. Amer. Soc. Hort. Sci. 120:123-127.

Kucera, B., M.A. Cohn, and G. LeubnerMetzger. 2005. Plant hormone interactions during seed dormancy release and germination. Seed Sci. Res. 15:281-307. 